\title{
Prognostic significance of minichromosome maintenance mRNA expression in human lung adenocarcinoma
}

\author{
SHU LI ${ }^{1,2}$, ZHOU JIANG ${ }^{2}$, YIRUN $\mathrm{LI}^{3}$ and YANG XU ${ }^{1}$ \\ ${ }^{1}$ Department of Hematology, ${ }^{2}$ Cancer Institute (Key Laboratory of Cancer Prevention and Intervention, \\ China National Ministry of Education), The Second Affiliated Hospital, Zhejiang University School of Medicine, \\ Hangzhou, Zhejiang 310009; ${ }^{3}$ Department of General Surgery, Sir Run Run Shaw Hospital, \\ Zhejiang University School of Medicine, Hangzhou, Zhejiang 310000, P.R. China
}

Received February 20, 2019; Accepted August 9, 2019

DOI: $10.3892 /$ or.2019.7330

\begin{abstract}
The minichromosome maintenance (MCM) gene family plays an essential role in DNA replication and cell cycle progression. However, MCM gene expression has not been well-studied in lung adenocarcinoma (LUAD). In the present study, the expression, prognostic value and functions of MCMs in LUAD were investigated using several databases and bioinformatic tools, including Oncomine, GEPIA, cBioPortal, CancerSEA and Kaplan-Meier plotter. It was demonstrated that the mRNA expression of MCM2, MCM4 and MCM10 were significantly increased in patients with LUAD. High mRNA expression of MCM2-5, MCM8 and MCM10 were associated with poor overall survival and progression-free survival. High MCM4 expression was associated with adverse post-progression survival. In addition, the Human Protein Atlas database showed that MCM protein expression was consistent with the mRNA expression. These results demonstrate that MCM2, MCM4 and MCM10 are potential prognostic markers and therapeutic targets for LUAD.
\end{abstract}

\section{Introduction}

Lung cancer was the leading cause of cancer-related deaths worldwide in $2016(1,2)$. Lung adenocarcinoma (LUAD), a histological type of non-small-cell lung cancer, accounts for a major proportion of this disease (3). In the last decade, the development of targeted therapy using tyrosine kinase inhibitors and crizotinib has led to improved clinical outcomes in LUAD patients with alterations in the epidermal growth factor receptor gene or fusion of echinoderm microtubule-associated

Correspondence to: Professor Yang Xu, Department of Hematology, The Second Affiliated Hospital, Zhejiang University School of Medicine, 9 Outpatient Building, 88 Jiefang Road, Hangzhou, Zhejiang 310009, P.R. China

E-mail: yxu@zju.edu.cn

Key words: minichromosome maintenance family, marker, mRNA, prognosis, lung adenocarcinoma, database protein-like 4 and anaplastic lymphoma kinase, respectively (4-7). More recently, immunotherapy has been developed and increasingly used in patients with lung cancer, including immune checkpoint inhibitors that target programmed cell death 1 ligand 1 (PD-L1)-expressing tumor cells by blocking PD-L1/PD-1 signaling $(8,9)$. Despite recent advances in targeted therapy and immunotherapy, the prognosis of LUAD remains poor (10). It has become a research trend to explore novel molecular biomarkers or therapeutic targets in the era of precision medicine (11). In fact, databases based on large-scale, genome-wide association studies have facilitated the discovery of new biomarkers for cancer management (12).

The minichromosome maintenance (MCM) family consists of 8 highly conserved members, including MCM2-7, MCM8 and MCM10 (13). MCM2-7 form the MCM complex, a hexamer that binds to DNA and functions in the initiation of DNA replication $(14,15)$. MCM8 is unique in that it serves as a DNA helicase during replication elongation, but not initiation (16). MCM10 helps to regulate DNA replication elongation (17). In line with their essential roles in DNA replication, MCM genes have become valuable biomarkers for cancer diagnosis and prognosis prediction (18-21). Previous studies have shown that MCM2, MCM4 and MCM7 regulate cell proliferation in non-small cell lung cancer (NSCLC) (22-24). However, the functions of other MCM family members remain unclear, and a comprehensive mRNA profiling of MCM family members in lung cancer has not been performed. In the present study, database research and bioinformatic analysis were performed to determine the prognostic significance of MCM mRNA expression in patients with lung cancer.

\section{Materials and methods}

Ethics statement. This study was performed in accordance with standard guidelines, and was approved by the Ethics Committee of the Second Affiliated Hospital, Zhejiang University School of Medicine (Zhejiang, China). The datasets were retrieved from published literature in which informed consent was obtained from patients.

Oncomine analysis. The Oncomine database (www.oncomine. org) is a bioinformatics tool for collecting, standardizing, 
analyzing and delivering cancer transcriptome data to the biomedical research community. It was used to compare the transcription levels of MCMs between cancer specimens and paracarcinoma tissue. In Oncomine, Student's t-test is generated for two class differential expression analyses (25). In the present study, $\mathrm{P}<0.01$ and an absolute fold-change $\geq 1.5$ were selected as the cut off values to analyze the gene expression chart of each MCM family member.

Gene expression profiling interactive analysis (GEPIA) database. GEPIA (http://gepia.cancer-pku.cn/) is a web tool that provides fast and customizable functionalities based on data from The Cancer Genome Atlas (TCGA; https://tcgadata.nci.nih.gov/tcga/) and the Genotype-Tissue Expression project (GTEx; https://www.gtexportal.org/home/index.html). Differential analysis was performed using one-way ANOVA, using disease state or tumor stage as the variable for calculating differential expression (26). In the current study, GEPIA was used to represent the differential expression of MCMs graphically between LUAD and paracarcinoma tissues and the association between the expression of MCMs and tumor stages in patients with LUAD (27).

The human protein atlas database. The Human Protein Atlas (https://www.proteinatlas.org/) is a database of immunohistochemistry (IHC)-based protein expression profiles in normal tissue, cancer and cell lines (28). IHC images of MCM protein expression in clinical specimens of patients with LUAD and paracarcinoma tissues were obtained from the Human Protein Atlas database.

Kaplan-meier plotter. The Kaplan-Meier Plotter tool (www.kmplot.com) includes survival information of 866 patients with LUAD. The prognostic value of MCM expression was assessed by overall survival (OS), progression-free survival (PFS) and post-progression survival (PPS), using the hazard ratio (HR), 95\% confidence intervals (CI) and log-rank P-value. In the analysis, patient samples were split into high expression group and low expression group based on the median mRNA levels of the MCMs. The prognostic value of a gene was assessed by univariate Cox regression analysis (29). JetSet scores were used to select a single representative probe set for each gene (30). In the current study, only the probe sets with best JetSet scores for MCMs were selected to produce Kaplan-Meier plots. The one-to-one matches between MCM genes and probe sets, identified by Affymetrix IDs, were as follows: MCM2 and 272107_s_at; MCM3 and 201555_at; MCM4 and 222036_s_at; MCM5 and 216237_s_at; MCM6 and 238977_at; MCM7 and 208795_s_ at; MCM8 and 224320_s_at; and MCM10 and 223570_at. The relevant concepts are defined as follows: OS, time from diagnosis to death; PFS, time from diagnosis to tumor progression; PPS, time from progression to death; HR $>1$, worse survival prognosis for the group with high mRNA expression; $\mathrm{HR}<1$, unfavorable survival prognosis in the low mRNA expression group; 95\% CI does not cross 1, mRNA expression is associated with survival rate. As not all gene expression levels were available in all patients and only the JetSet probes were included in the study, the sample sizes vary for each survival analysis.
Table I. Comparison of mRNA expression of MCMs in lung adenocarcinoma and normal lung tissues from the Oncomine database.

\begin{tabular}{|c|c|c|c|c|}
\hline Gene & Cases, $\mathrm{n}$ & $\begin{array}{c}\text { Fold } \\
\text { change }\end{array}$ & P-value & (Refs.) \\
\hline \multirow[t]{7}{*}{ MCM2 } & 110 & 3.251 & $3.46 \times 10^{-13}$ & (33) \\
\hline & 116 & 2.436 & $3.20 \times 10^{-17}$ & (34) \\
\hline & 66 & 2.411 & $2.36 \times 10^{-6}$ & (35) \\
\hline & 246 & 2.120 & $3.44 \times 10^{-11}$ & $(36)$ \\
\hline & 107 & 1.993 & $7.61 \times 10^{-11}$ & (37) \\
\hline & 39 & 1.846 & $6.36 \times 10^{-5}$ & (38) \\
\hline & 96 & 1.668 & $4.35 \times 10^{-6}$ & (39) \\
\hline \multirow[t]{3}{*}{ MCM3 } & 46 & 1.992 & $5.27 \times 10^{-5}$ & $(40)$ \\
\hline & 116 & 1.617 & $4.13 \times 10^{-16}$ & $(34)$ \\
\hline & 110 & 1.591 & $1.34 \times 10^{-7}$ & (33) \\
\hline \multirow[t]{7}{*}{ MCM4 } & 110 & 3.390 & $3.60 \times 10^{-15}$ & (33) \\
\hline & 66 & 2.649 & $7.09 \times 10^{-10}$ & (35) \\
\hline & 116 & 2.618 & $1.36 \times 10^{-18}$ & (34) \\
\hline & 107 & 2.403 & $8.50 \times 10^{-19}$ & (37) \\
\hline & 96 & 1.982 & $3.80 \times 10^{-20}$ & (39) \\
\hline & 46 & 1.923 & $1.02 \times 10^{-4}$ & $(40)$ \\
\hline & 246 & 1.668 & $6.17 \times 10^{-12}$ & $(36)$ \\
\hline \multirow[t]{2}{*}{ MCM5 } & 46 & 1.810 & $4.58 \times 10^{-6}$ & $(40)$ \\
\hline & 110 & 1.544 & $1.09 \times 10^{-8}$ & (33) \\
\hline \multirow[t]{6}{*}{ MCM6 } & 46 & 2.932 & $1.15 \times 10^{-4}$ & $(40)$ \\
\hline & 110 & 2.114 & $1.69 \times 10^{-12}$ & (33) \\
\hline & 39 & 2.012 & $4.04 \times 10^{-6}$ & (38) \\
\hline & 107 & 1.830 & $2.25 \times 10^{-15}$ & (37) \\
\hline & 116 & 1.797 & $2.63 \times 10^{-12}$ & (34) \\
\hline & 66 & 1.760 & $3.20 \times 10^{-6}$ & (35) \\
\hline \multirow[t]{5}{*}{ MCM7 } & 110 & 4.547 & $4.11 \times 10^{-8}$ & (33) \\
\hline & 107 & 1.628 & $2.08 \times 10^{-10}$ & (37) \\
\hline & 66 & 1.579 & $1.72 \times 10^{-5}$ & (35) \\
\hline & 116 & 1.551 & $1.24 \times 10^{-10}$ & (34) \\
\hline & 39 & 1.513 & $1.60 \times 10^{-4}$ & $(38)$ \\
\hline MCM8 & 110 & 1.987 & $1.37 \times 10^{-8}$ & (33) \\
\hline \multirow[t]{4}{*}{ MCM10 } & 110 & 6.446 & $7.96 \times 10^{-8}$ & $(33)$ \\
\hline & 246 & 1.792 & $1.92 \times 10^{-9}$ & $(36)$ \\
\hline & 116 & 1.733 & $5.36 \times 10^{-14}$ & (34) \\
\hline & 107 & 1.509 & $1.22 \times 10^{-9}$ & (37) \\
\hline
\end{tabular}

MCM, minichromosome maintenance; Ref, reference.

cBioPortal for cancer genomics (cBioPortal) dataset. cBioPortal (http://cbioportal.org) is based on other authoritative databases, including the Gene Expression Omnibus (GEO; http://www.ncbi.nlm.nih.gov/geo/) and TCGA database. cBioPortal is a web resource for exploring, visualizing and analyzing multidimensional cancer genomics data. The genomic profile of each gene includes mutations, putative copy-number alterations and mRNA expression $z$-scores. The $\mathrm{z}$ score for each gene is the normalized expression of mRNA 


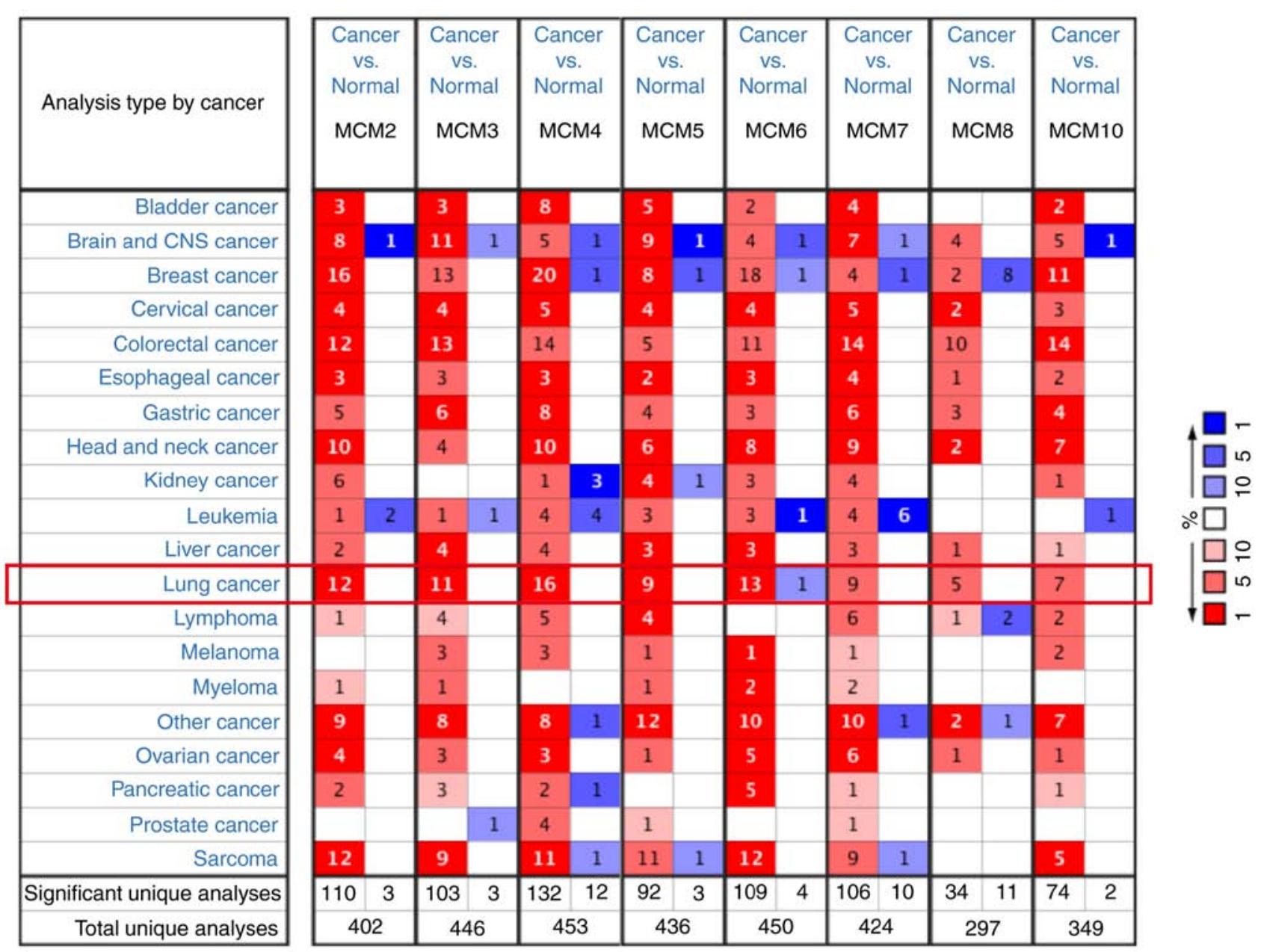

Figure 1. Expression of MCMs in cancer vs. normal tissues from the Oncomine database. Color is determined by the highest gene rank percentile genes based on log fold-change; red indicates upregulation and blue represents downregulation. The values within each cell represent the number of databases that met the filter criteria for differently expressed MCMs in cancer and normal tissues. MCM, minichromosome maintenance.

using RNA-Seq by expectation maximization count estimates method. The co-expression of each gene pair was performed by Fisher's exact test (31) and the network was constructed according to the correlation.

Cancer SEA. CancerSEA (http://biocc.hrbmu.edu.cn/ CancerSEA/) is a dedicated database for comprehensively exploring distinct functional states of cancer cells at the single-cell level. The cancer-related single cell RNA-seq (scRNA-seq) datasets for human samples in CancerSEA were collected from the Sequence Read Archive (https://www. ncbi.nlm.nih.gov/sra), the GEO database and ArrayExpress (https://www.ebi.ac.uk/arrayexpress/). For each cancer-related scRNA-seq dataset, the original paper was read and the corresponding metadata was extracted, including the cancer types and sources, including patient-derived xenograft (PDX) and circulating tumor cell (CTC). Thus, CancerSEA contained the cancer single-cell functional state atlas of 41,900 cancer single cells from 25 cancer types. LUAD chips and PDX are numbered with Exp and LC-PT as the headers, respectively. For each single-cell dataset derived from PDX and CTC tumor tissue, significant correlations between gene expression and functional state activities were analyzed using Spearman's rank correlation test with false discovery rate correction for multiple comparisons (32). In the present study, CancerSEA was used for the functional analysis of MCMs.

\section{Results}

Transcriptional levels of MCMs in patients with LUAD. The MCM transcriptional levels in cancers were compared with those in paracarcinoma tissues using the Oncomine database. As presented in Fig. 1, MCMs were generally overexpressed in most tumors. In lung cancer, all MCM members were upregulated in cancer tissues, except MCM6, which was downregulated in one dataset, which may be due to the limited numbers of samples. MCM mRNA expression in LUAD and paracarcinoma tissues are summarized in Table I. The mRNA levels of all MCM members were significantly increased in LUAD tissues. MCM2 overexpression was present in 8 databases (33-39), followed by MCM4 in 7 datasets $(33-37,39,40)$. MCM10 is the most upregulated member with a fold increase of 6.446 in the dataset from a study by Hou et al (33).

MCM mRNA expression is associated with pathological stages of $L U A D$. As with Oncomine, GEPIA analysis indicated that expression of MCM2-7, MCM8 and MCM10 was higher 
A
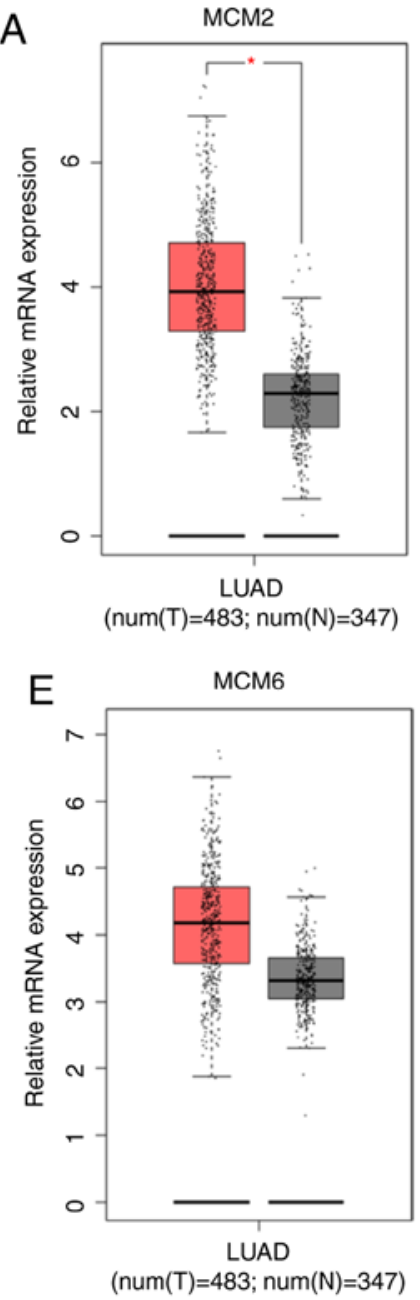

B

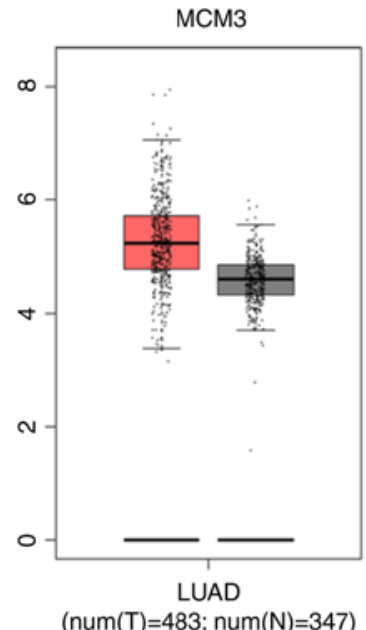

(num $(T)=483 ; \operatorname{num}(N)=347)$

$\mathrm{F}$

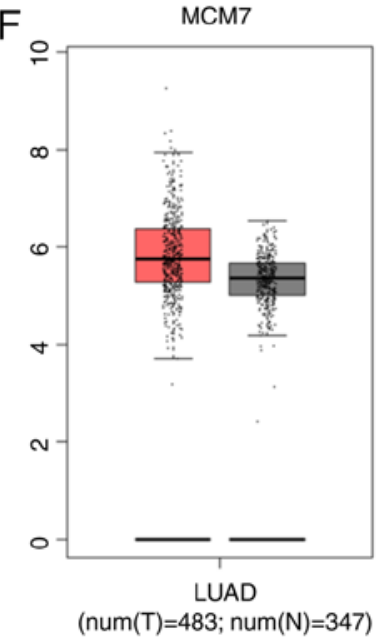

C

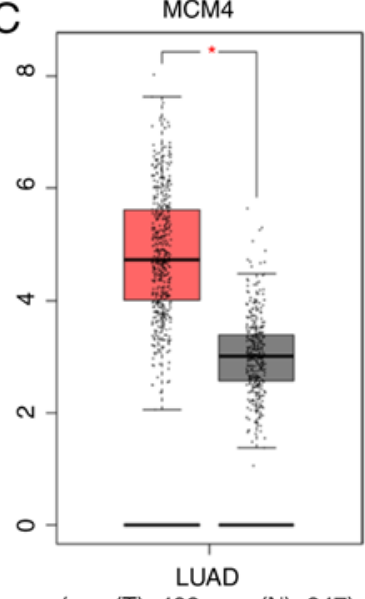

(num $(T)=483 ;$ num $(N)=347$ )

G

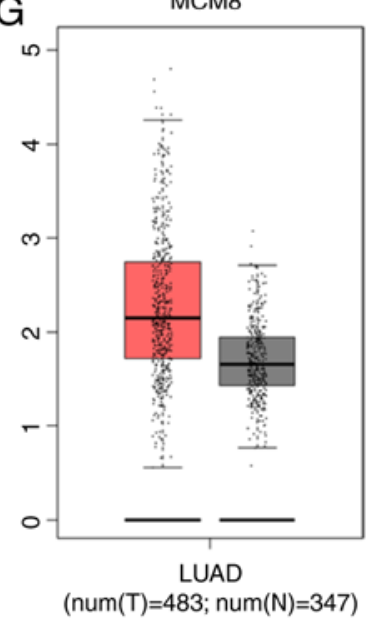

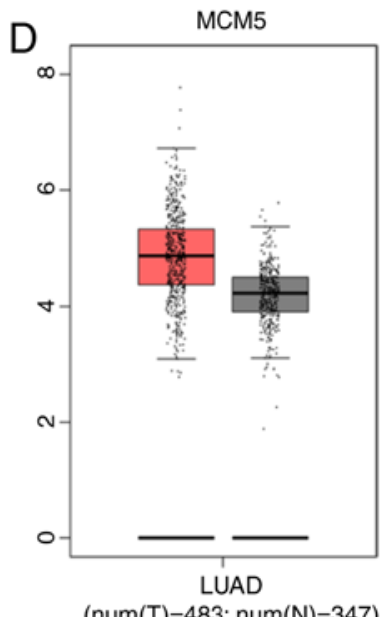

(num $(T)=483 ; \operatorname{num}(N)=347$ )

$\mathrm{H}$

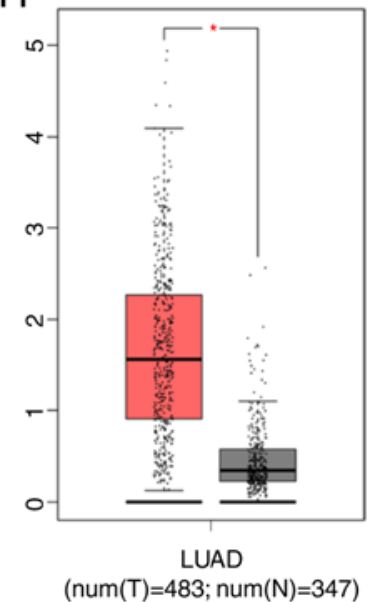

$\square$ Tumor tissue

Normal tissue

Figure 2. Expression of MCMs in lung adenocarcinoma and normal tissues analyzed using GEPIA. (A) MCM2, (B) MCM3, (C) MCM4, (D) MCM5, (E) MCM6, (F) MCM7, (G) MCM8 and (H) MCM10. In the box plots, the thick line in the middle represents the median, and the upper and lower limits of the box represent the third and first quartile respectively. The top and bottom of the error bars represent the maximum and minimum values of data, respectively; outliers were considered to be $>1.5$ quartile spacing, and were excluded. " $\mathrm{P}<0.05$. MCM, minichromosome maintenance; $\mathrm{T}$, tumor; $\mathrm{N}$, normal; num, number.

in LUAD than in lung tissues (Fig. 2), although statistically significant differences were observed for MCM2 (Fig. 2A), MCM4 (Fig. 2C) and MCM10 (Fig. 2H) only. The association between MCM expression and LUAD pathological stage was then investigated. As presented in Fig. 3, the mRNA levels of MCM2 ( $\mathrm{P}=0.0407$; Fig. 3A), MCM4 ( $\mathrm{P}=0.00101$; Fig. 3C), MCM6 ( $\mathrm{P}=0.0096$; Fig. 3E), MCM7 ( $\mathrm{P}=0.00595$; Fig. 3F) and MCM $10(\mathrm{P}=0.00598$; Fig. $3 \mathrm{H})$ significantly different between the tumor stages I to IV. Similar trends occurred for MCM3 (P=0.0605; Fig. 3B) and MCM5 ( $\mathrm{P}=0.0957$; Fig. 3D). However, there was no association between MCM8 $(\mathrm{P}=0.231$; Fig. 3G) and tumor stage.

Protein expression levels of MCMs in patients with LUAD. To examine whether MCM protein was also differentially expressed in LUAD tissues, immunohistochemical staining images for the MCM proteins in LUAD and paracarcinoma tissues were obtained from the Human Protein Atlas database (Fig. 4). Consistent with RNA expression data, the results demonstrated that MCM2, MCM5, MCM6 and MCM7 protein levels were higher in LUAD tissue compared with normal tissue, whereas MCM3, MCM4 and MCM10 proteins were only slightly increased in LUAD tissue.

The prognostic significance of MCMs in patients with LUAD. Using the Kaplan-Meier plotter, the prognostic significance of the mRNA expression of MCMs in patients with LUAD was determined. Seven MCM members were significantly associated with reduced OS in patients with LUAD (Fig. 5A). Survival curves are presented in Fig. 5B-I. High expression of MCM2 (Fig. 5B; HR, 1.33; 95\% CI, 1.05-1.67; P=0.018), MCM3 (Fig. 5C; HR, 2.20; 95\% CI, 1.72-2.82; $\mathrm{P}=1.1 \times 10^{-10}$ ), MCM4 (Fig. 5D; HR, 2.27; 95\% CI, 1.78-2.90; $\mathrm{P}=1.1 \times 10^{-11}$ ), MCM5 (Fig. 5E; HR, 1.34; 95\% CI, 1.06-1.79; $\mathrm{P}=0.014$ ), MCM7 (Fig. 5G; HR, 1.29; 95\% CI, 1.02-1.63; P=0.031), MCM8 (Fig. 5H; HR, 1.34; 95\% CI, 1.05-1.71; $\mathrm{P}=0.019$ ) and MCM10 (Fig. 5I; HR, 1.29; 95\% CI, 1.02-1.63; P=0.031) were associated with worse OS, while MCM6 was not associated with altered OS (Fig. 5F; HR, 1.08; 95\% CI, 0.85-1.37; $\mathrm{P}=0.530$ ). 
A
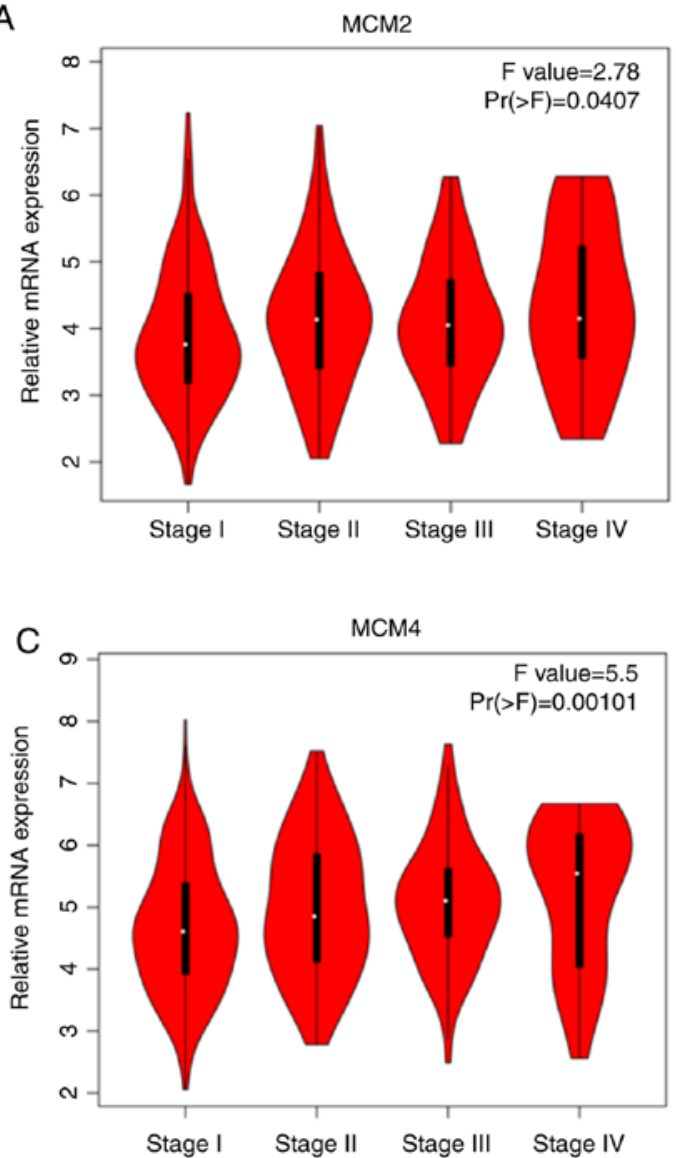

E
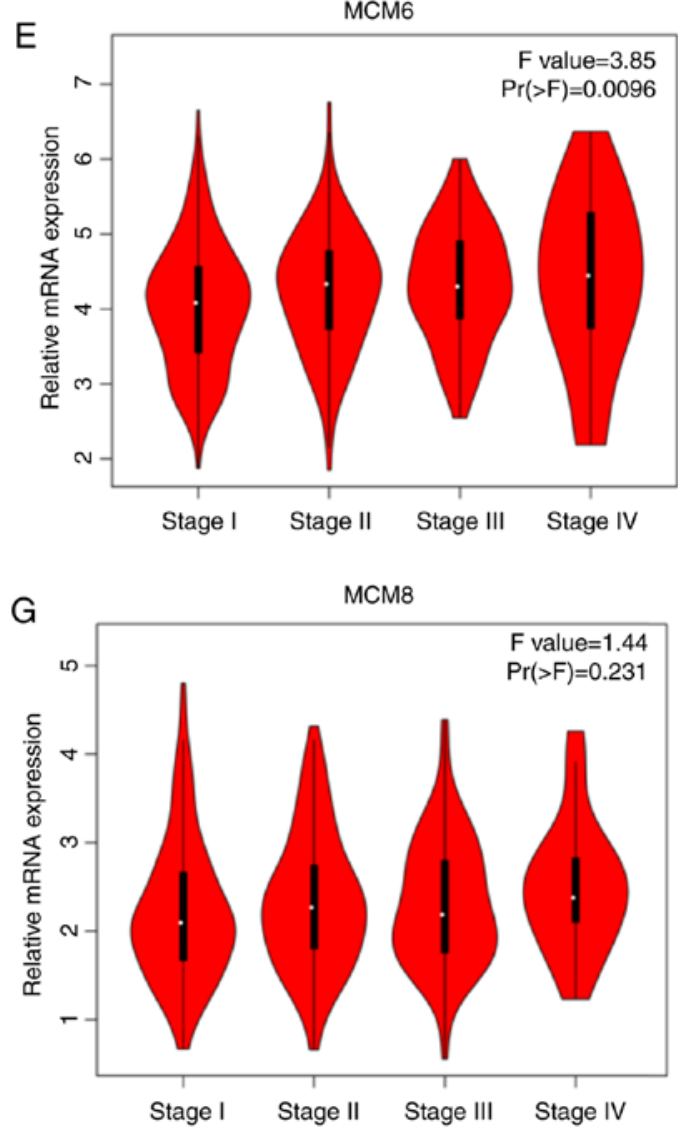

B

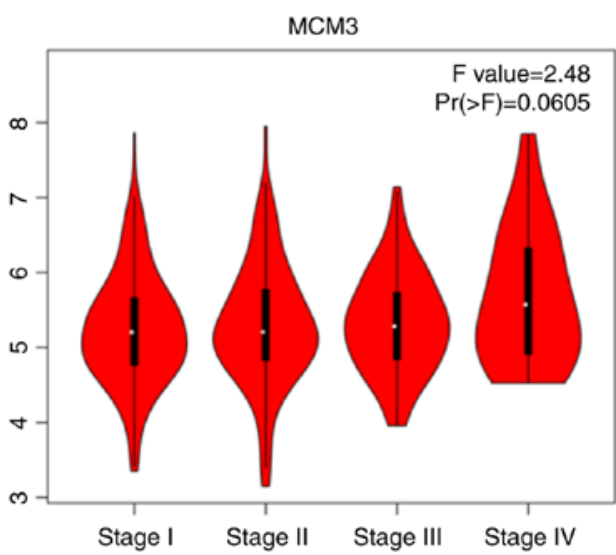

D
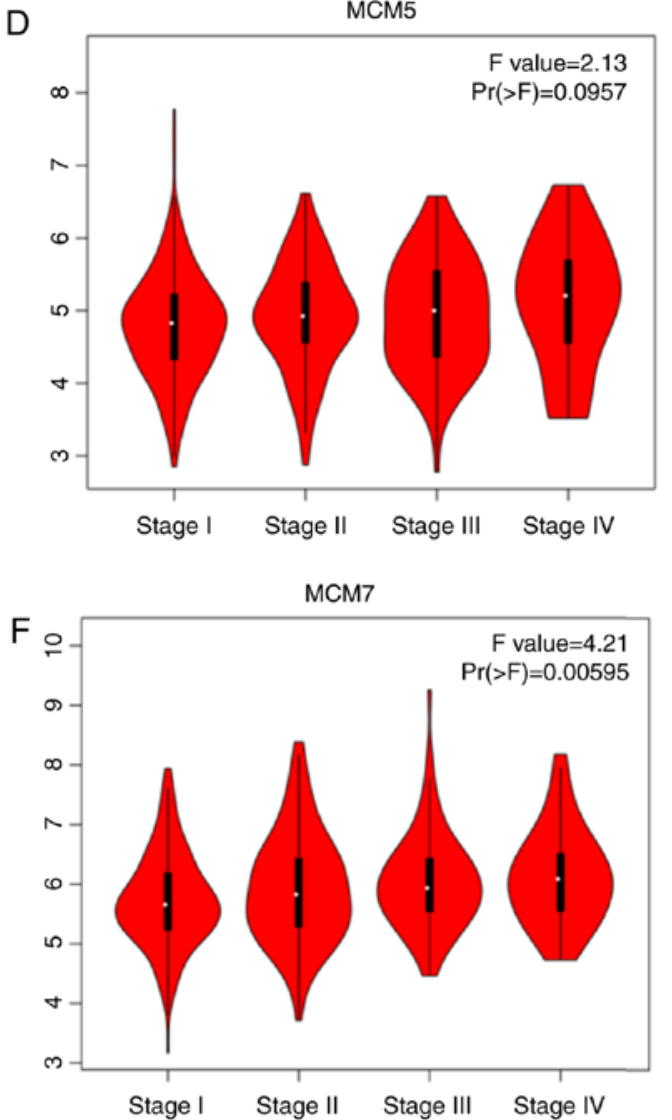

$\mathrm{H}$

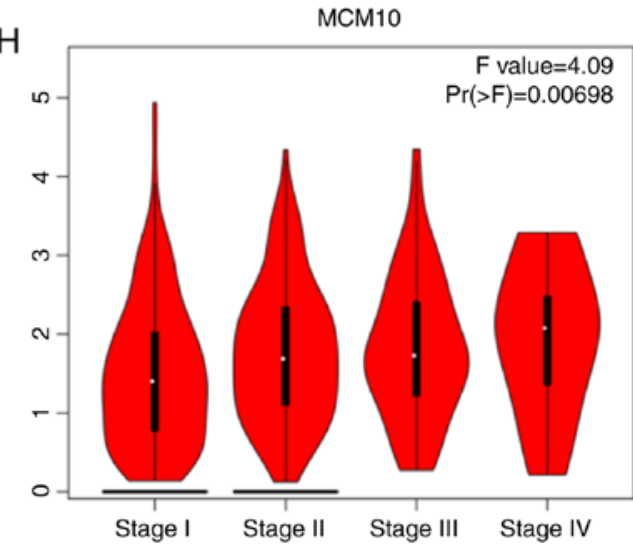

Figure 3. Association of mRNA expression of MCMs and tumor stages in patients with lung adenocarcinoma analyzed using GEPIA. (A) MCM2, (B) MCM3, (C) MCM4, (D) MCM5, (E) MCM6, (F) MCM7, (G) MCM8 and (H) MCM10. In the violin plots, the white dots represent the median; the black bars represent the $95 \%$ confidence intervals; the black lines represent the interquartile range; and the width of the red shapes represent the density of distribution. MCM, minichromosome maintenance. F-value, the statistical value of F test; $\operatorname{Pr}(>\mathrm{F}), \mathrm{P}$-value. 

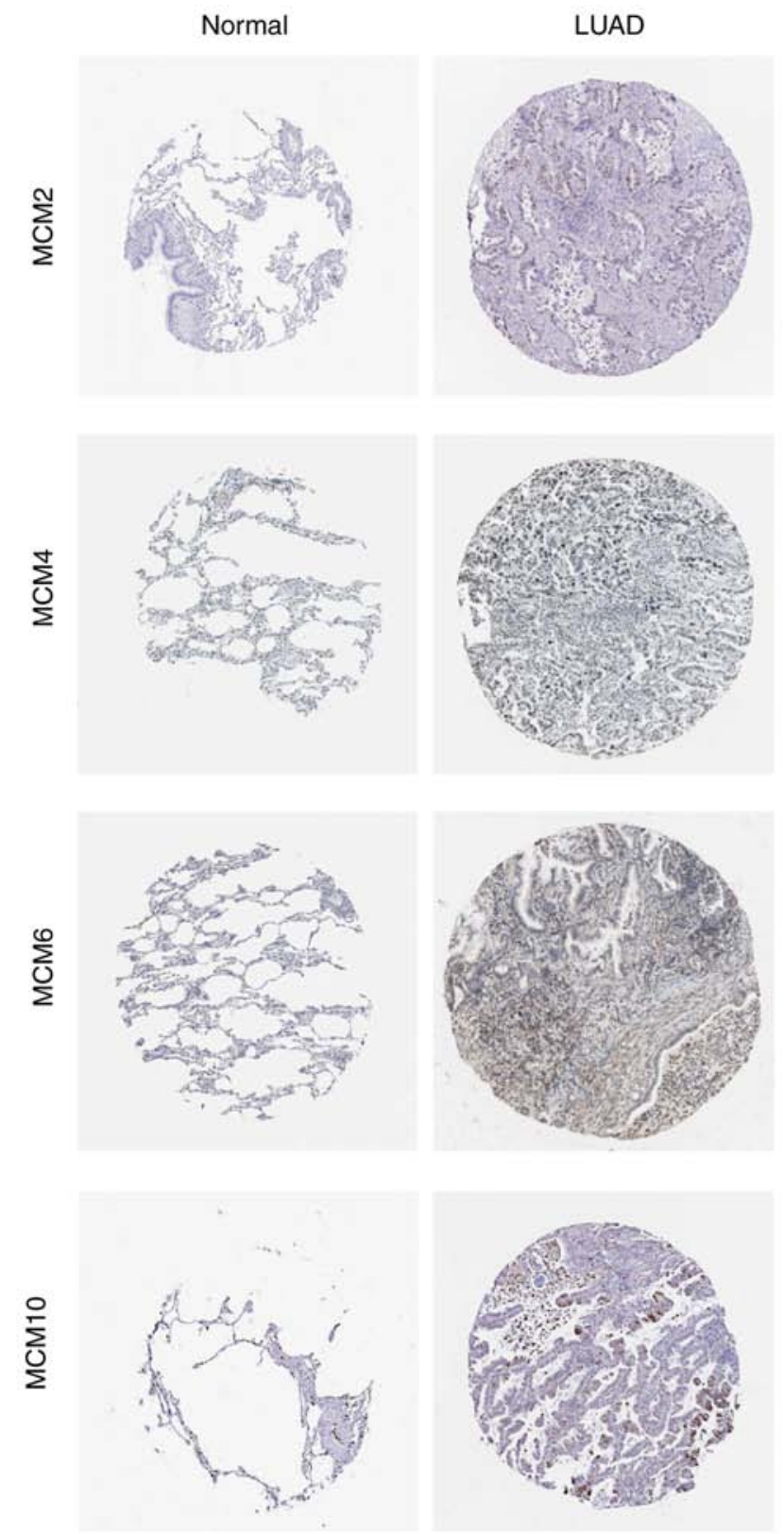
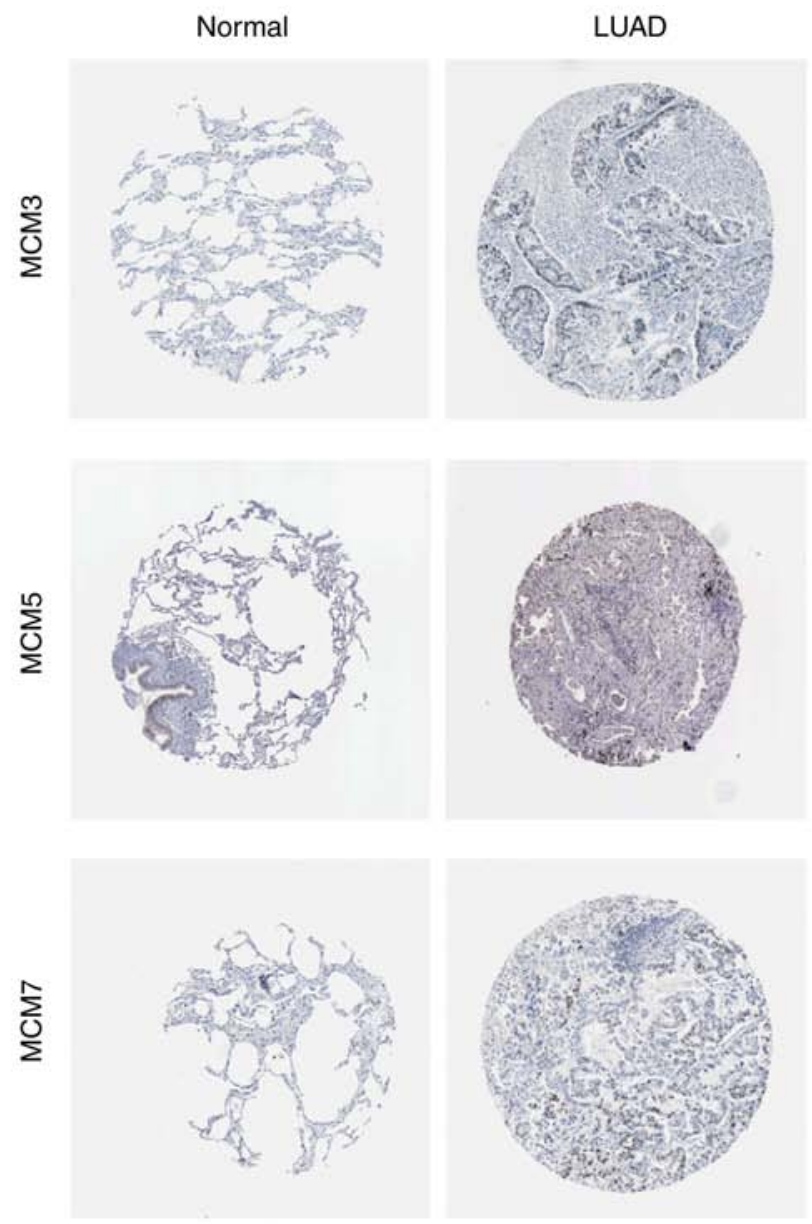

Figure 4. Immunohistochemical staining for protein expression of MCMs in tissues from patients with LUAD and normal tissues, obtained from The Human Protein Atlas. MCM, minichromosome maintenance; LUAD, lung adenocarcinoma.

Similarly, high expression of MCM2 (Fig. 6B; HR, 1.62; 95\% CI, 1.18-2.22; P=0.003), MCM3 (Fig. 6C; HR, 1.39; 95\% CI, 1.02-1.90; $\mathrm{P}=0.037$ ), MCM4 (Fig. 6D; HR, 2.38; 95\% CI, 1.72-3.31; $\mathrm{P}=8.3 \times 10^{-8}$ ), MCM5 (Fig. 6E; HR, 1.42; 95\% CI, 1.04-1.95; P=0.027), MCM8 (Fig. 6H; HR, 1.44; 95\% CI, 1.04-1.99; P=0.027) and MCM10 (Fig. 6I; HR, 1.94; 95\% CI, $1.40-2.71 ; \mathrm{P}=6.5 \times 10^{-5}$ ) was significantly associated with reduced PFS. Additionally, high MCM4 mRNA expression also indicated adverse PPS (Fig. 6D; HR, 1.62; 95\% CI, 1.01-2.59; P=0.043). Other MCMs were not associated with PFS or PPS (Figs. 6 and 7).

MCM expression changes in LUAD and the network within each MCM or with other genes. With the cBioPortal online tool, the alterations, correlations and networks of MCMs in LUAD were analyzed. Of the LUAD samples, $39 \%$ had altered MCMs, and the most common genetic change was gene amplification (Fig. 8A). The distribution of genetic alterations for individual MCMs indicated that nearly $15 \%$ of LUAD cases had MCM4 amplification (Fig. 8B). Significant and positive correlations were observed between the MCMs (Fig. 8C). Among them, MCM2 and MCM6 had the highest positive correlation with a Spearman's correlation coefficient of 0.848. MCM10 exhibited the tightest association with all other MCMs, with a median Spearman's correlation coefficient of 0.771 . Next, the network for MCMs and the genes frequently altered with MCMs was constructed (Fig. 8D). The majority of the genes frequently altered with MCMs were cell cycle-related or involved in DNA damage/repair, such as ATM serine/threonine kinase, RAD1 checkpoint DNA exonuclease, cyclin dependent kinase 1, cyclin $\mathrm{A} 1$ and replication factor $\mathrm{C}$ subunit 5, suggesting that the MCM family is critical for maintenance of genome integrity. 

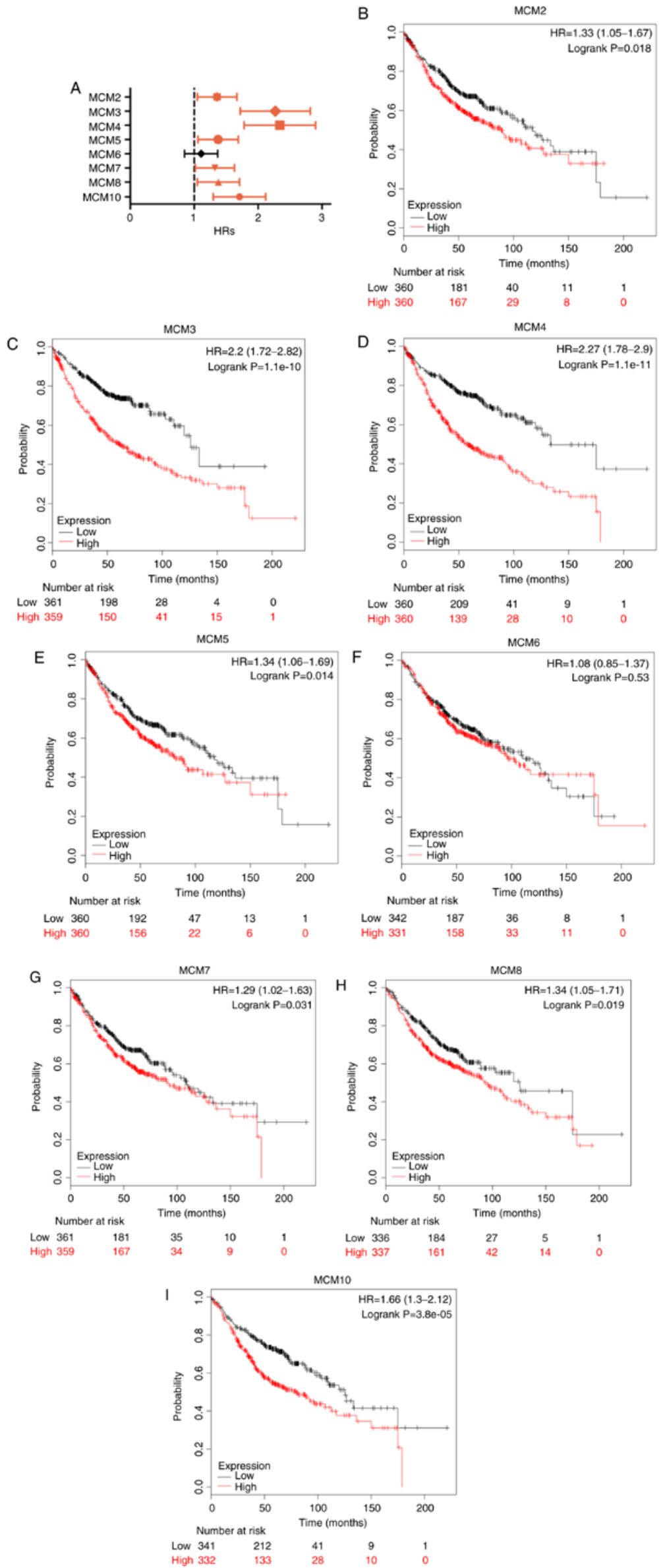

Figure 5. OS of LUAD patients with high and low mRNA expression of MCM, analyzed using the Kaplan-Meier Plotter tool. (A) Prognostic HRs of individual MCM members in LUAD; error bars represent the 95\% confidence intervals. (B-I) OS curves of MCM2, MCM3, MCM4, MCM5, MCM6, MCM7, MCM8 and MCM10 plotted for all patients $(\mathrm{n}=720)$. OS, overall survival; HR, hazard ratio; MCM, minichromosome maintenance; LUAD, lung adenocarcinoma. 

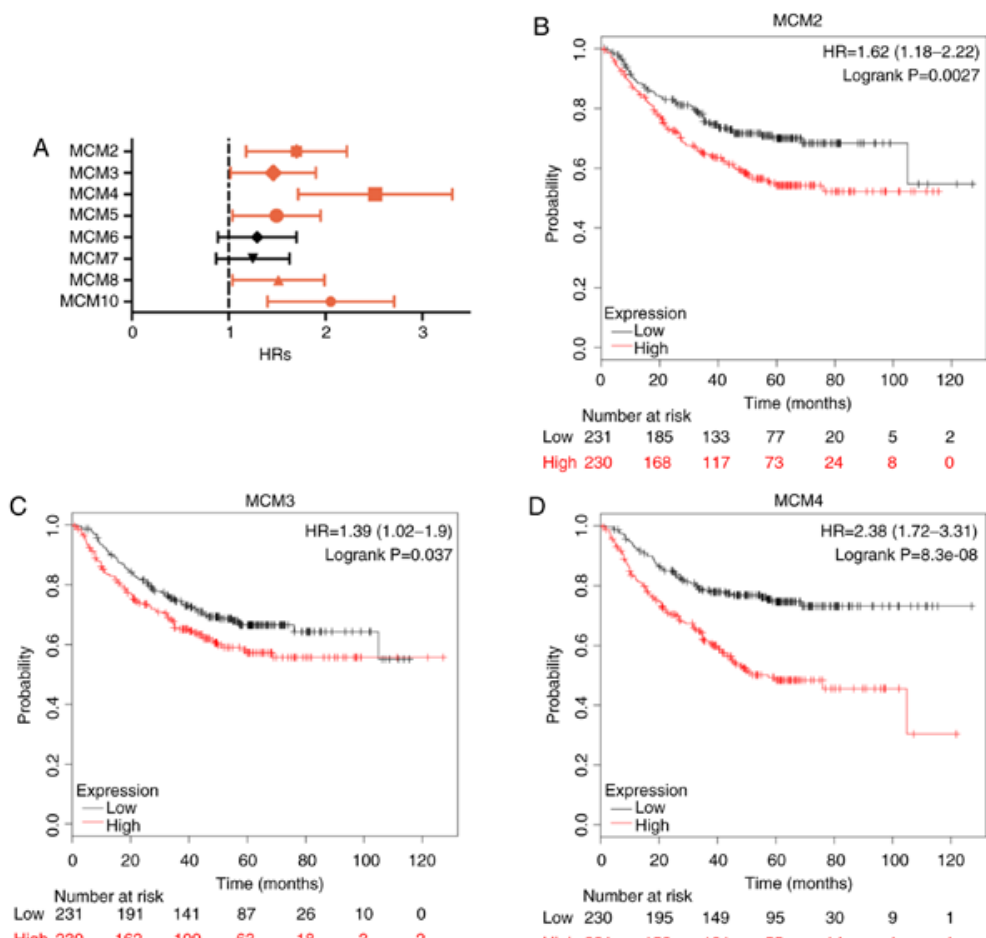

D
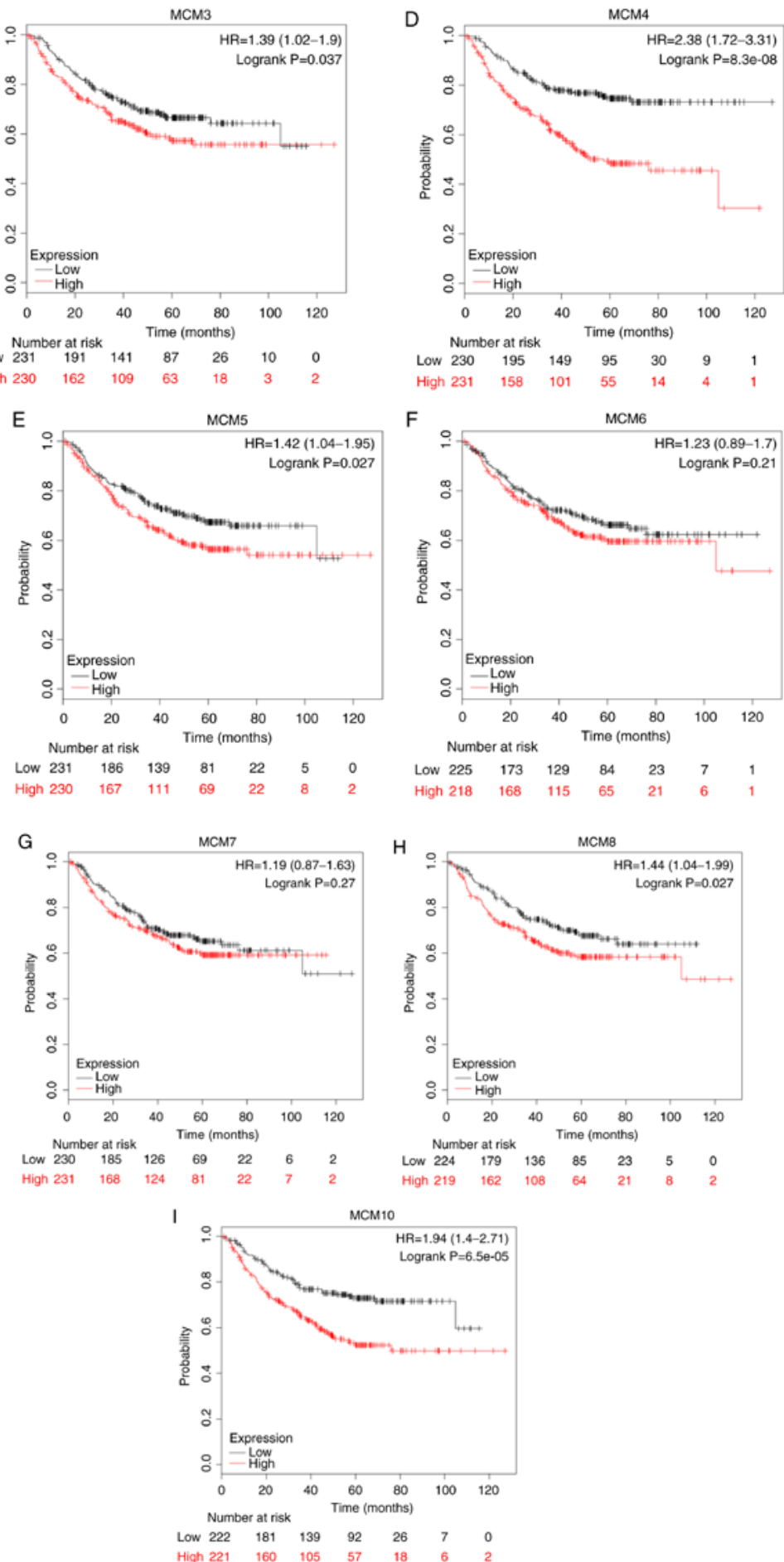

Figure 6. PFS in LUAD patients with high and low mRNA expression of MCM, analyzed using the Kaplan-Meier Plotter tool. (A) Prognostic HRs of individual MCM members in LUAD; error bars represent the 95\% confidence intervals. (B-I) PFS curves of MCM2, MCM3, MCM4, MCM5, MCM6, MCM7, MCM8 and MCM10 plotted for all patients ( $\mathrm{n}=461$ ). PFS, progression-free survival; HR, hazard ratio; MCM, minichromosome maintenance; LUAD, lung adenocarcinoma. 
A

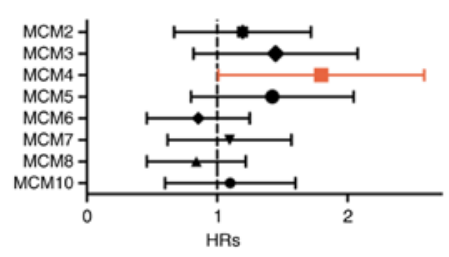

C

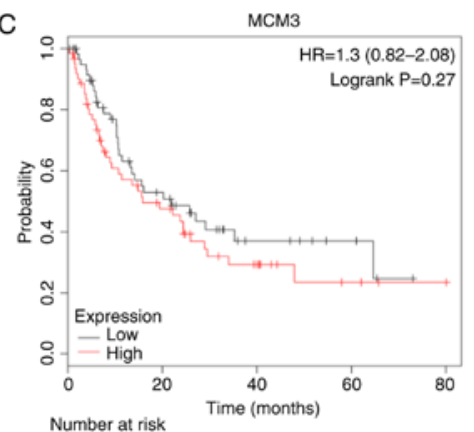

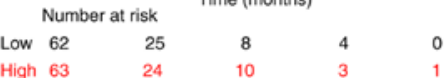

E

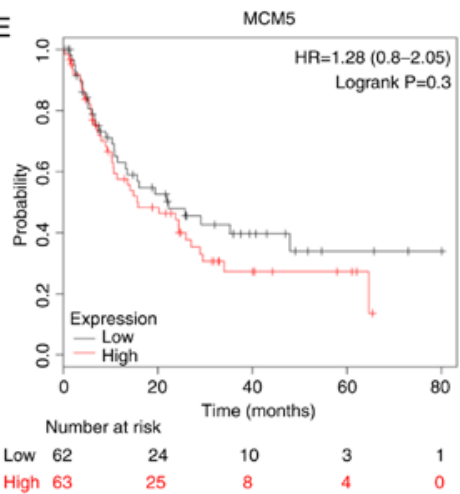

$\begin{array}{ccccc}\text { Low } 62 & 24 & 10 & 3 & 1 \\ \text { High } 63 & 25 & 8 & 4 & 0\end{array}$

G

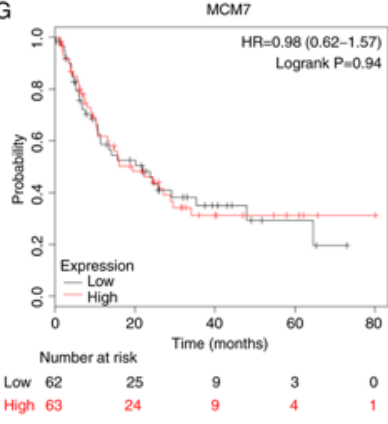

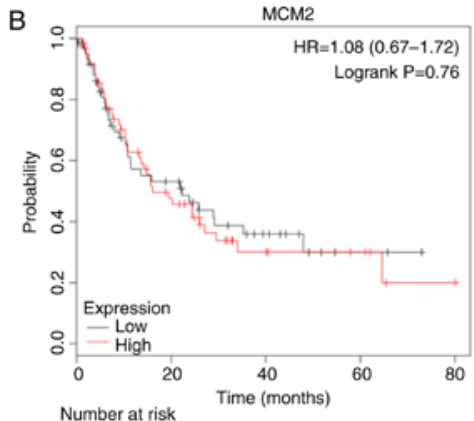

Low 62 umber at risk High $63 \quad 24$

D MCM4

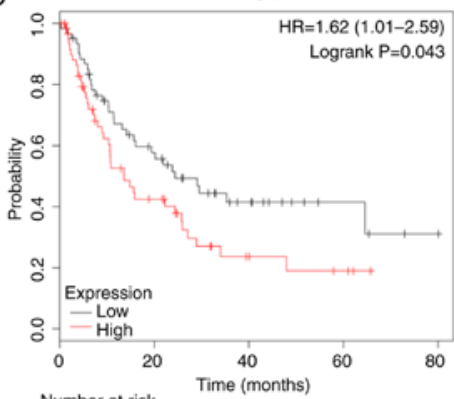

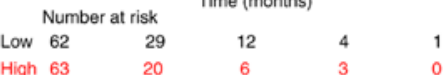

F

MCM6

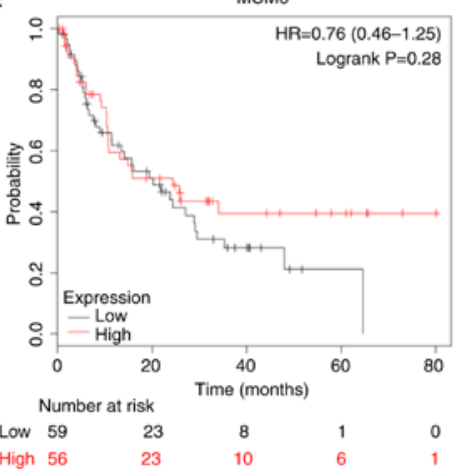

H MCMB

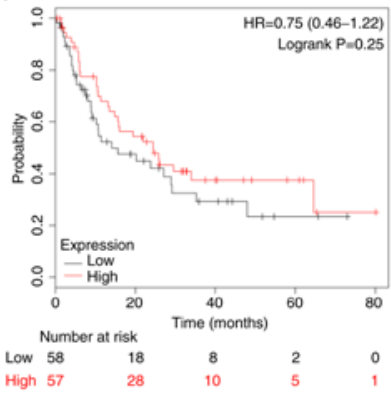

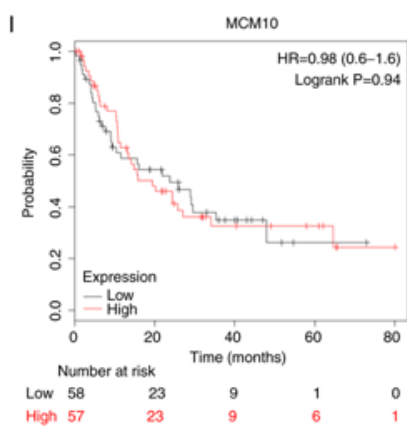

Figure 7. PPS of LUAD patients with high and low mRNA expression of MCM, analyzed using the Kaplan-Meier Plotter tool. (A) Prognostic HRs of individual MCM members in LUAD; error bars represent the 95\% confidence intervals. (B-I) PPS curves of MCM2, MCM3, MCM4, MCM5, MCM6, MCM7, MCM8 and MCM10 plotted for all patients $(n=125)$. PPS, post-progression survival; HR, hazard ratio; MCM, minichromosome maintenance; LUAD, lung adenocarcinoma. 


\section{B}
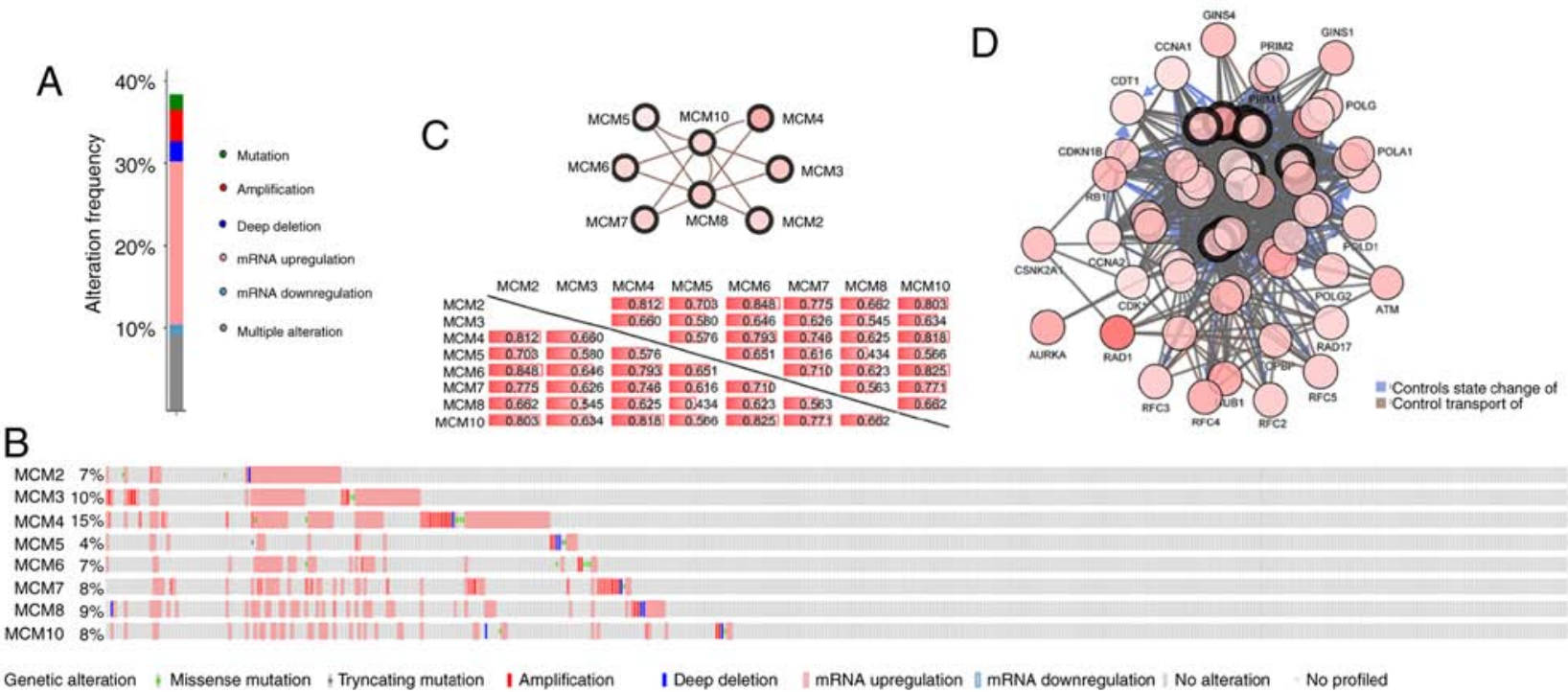

Figure 8. Analysis of MCM expression and mutation type and frequency in LUAD tissues using cBioPortal. (A) Summary of frequencies of alterations of MCMs in LUAD. (B) Genetic alterations of each MCM family member in LUAD patients. (C) Correlation between expression of MCM family members; Spearman's correlation coefficients are presented. Only those with a $\mathrm{P}<0.05$ were included in the image. (D) Network of MCM genes and the genes frequently altered with MCMs. MCM, minichromosome maintenance; LUAD, lung adenocarcinoma.

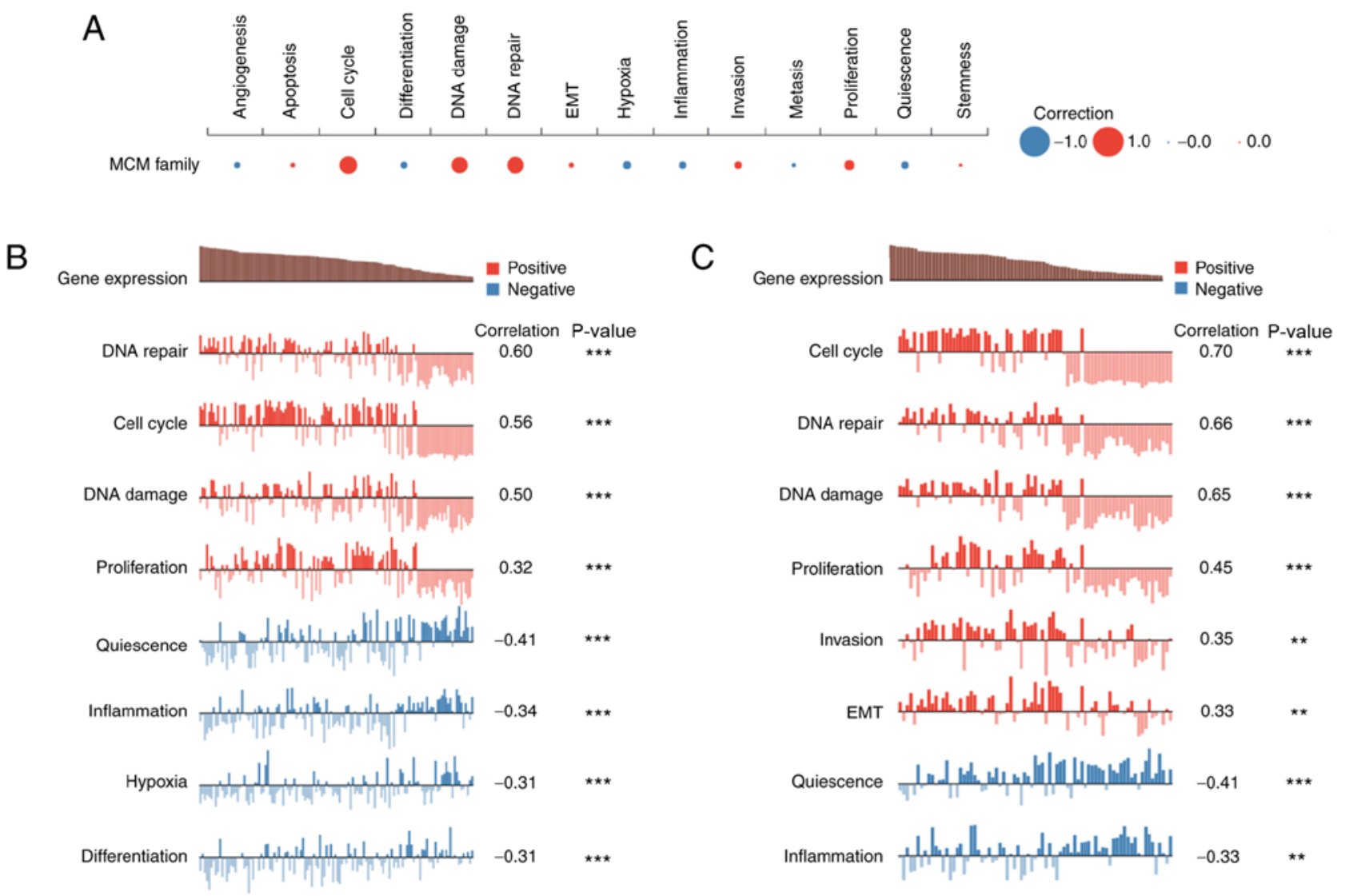

Figure 9. Functional analysis of MCMs with CancerSEA. (A) Functional relevance of MCMs in patients with LUAD. Bubble size represents the average correlation strength; red indicates a positive correlation and blue indicates a negative correlation. Detailed functional correlations in (B) LUAD chip and (C) in PXD model. ${ }^{* *} \mathrm{P}<0.01$ and ${ }^{* * *} \mathrm{P}<0.001$. MCM, minichromosome maintenance; LUAD, lung adenocarcinoma.

The functions of MCMs in single LUAD cell. Heterogeneity between cancer cells poses a major challenge for cancer diagnosis and treatment. Single-cell sequencing technology provides an unprecedented opportunity to accurately decipher the functional states of cancer cells at a single-cell resolution.

Using CancerSEA, the functions of MCMs in single LUAD cells were explored. MCM function was found to be mainly 
related to cell cycle, DNA damage or DNA repair (Fig. 9A). Kim (Exp0066) showed high expression of the MCM family was positively correlated with DNA repair, cell cycle, DNA damage and proliferation (Spearman's coefficients, 0.60, 0.56, 0.50 and 0.32 , respectively; $\mathrm{P}<0.001)(41)$. Correlation analysis also revealed a negative correlation of MCM expression and quiescence, inflammation, hypoxia and differentiation (Spearman's coefficient, $-0.41,-0.32,-0.31$ and -0.31 , respectively; $\mathrm{P}<0.001)$ (Fig. 9B). Similar results were observed in patient-derived xenograft (LC-PT-45) (41) (Fig. 9C).

\section{Discussion}

Uncontrolled cancer cell proliferation is usually accompanied by dysregulated DNA replication, and chemotherapeutic agents targeting replication machinery have been widely used for cancer treatment (42). MCMs, essential molecules in the initiation and elongation of DNA replication, are considered to be useful indicators of cell proliferation, and MCM alterations are more frequent in neoplastic cells than in non-neoplastic cells (43). Moreover, MCM proteins are expressed in rapidly dividing cells, but not in quiescent, aging or differentiated cells (44). Therefore, MCMs may have potential clinical application as markers for cancer screening. However, a comprehensive bioinformatics analysis of MCMs in LUAD has yet to be performed. To the best of our knowledge, this is the first study to explore the mRNA expression levels of the MCM family and their prognostic relevance for predicting OS, PFS and PPS in LUAD. Our findings highlight potential roles for MCMs in diagnosis and risk stratification in patients with LUAD.

MCM2 is the most studied MCM member that is upregulated in LUAD, and MCM2 dysregulation is associated with cell proliferation, cell cycle progression and migration (45). A significant correlation between MCM2 mRNA expression and LUAD stages was previously observed, and MCM2 was demonstrated to be the therapeutic target of lovastatin for NSCLC treatment (46). Additionally, Veena et al (47) reported that the MCM2 was present in lung tissues and in sputum, which is more accessible for MCM2 detection. However, the association between MCM2 expression and treatment outcomes of patients with NSCLC remains controversial $(44,48-50)$. In the present study, analysis using the Oncomine and GEPIA bioinformatics tools revealed that MCM2 expression was higher in LUAD tissues compared with that in normal tissues, and this finding was consistent with immunohistochemical staining for MCM2 in the Human Protein Atlas. Using the Kaplan-Meier Plotter, elevated MCM2 mRNA was found to be significantly associated with reduced OS and PFS in patients with LUAD.

MCM3 had been found to be differentially expressed in LUAD and adjacent normal tissue samples $(51,52)$; however, the role of MCM3 in NSCLC was unclear. Zhang et al (53) found that the PI3K inhibitor, LY294002, inhibited MCM3 expression in NSCLC cells, indicating that MCM3 is involved in the PI3K-Akt pathway. In the present study, MCM3 upregulation was also observed in LUAD tissues, and high MCM3 expression was associated with poor OS and PFS, but not PPS in patients with LUAD.

MCM4 overexpression is an oncogenic event in LUAD (54). A study by Kikuchi et al (55) showed that high MCM4 expression was associated with clinicopathological features of LUAD, but was not associated with survival. However, in the present study, high expression of MCM4 was associated with worse OS, PFS and PPS.

MCM5 is upregulated in lung squamous cell carcinoma, and patients with high MCM5 expression have reduced OS (43). In the current study, MCM5 was also found to be elevated in LUAD and was associated with adverse OS and PFS.

MCM6, together with Ki-67 and HuR, an RNA binding protein, were associated with poor prognosis in NSCLC $(44,56)$. However, no association was found between MCM6 expression and patient outcome in the current study.

MCM7 is involved in proliferation and signal transduction of the receptor of activated protein C kinase 1/Akt pathway (57). Moreover, pre-clinical research based on NSCLC cell lines showed that MCM7 and its targets, a cluster of miR-25, miR-93 and miR-106b, elicited oncogenic activity in lung cancer (58). MCM7 expression was also associated with worse prognosis in patients with NSCLC $(59,60)$. In the present study, high MCM7 expression was suggested to be a predictor for poor OS and PFS.

Little is known about the role of MCM8 and MCM10 in lung cancer. MCM8 is expressed in tissue with a high percentage of proliferating cells, such as lung and liver $(13,16)$. MCM10 promotes cell proliferation (17), is associated with poor prognosis and is considered to be a potential therapeutic target in breast and prostate cancer (61). In the current study, MCM8 mRNA, but not protein expression was found to be is higher in tumor compared with normal tissues. Similarly, MCM10 was also found to be overexpressed in LUAD. However, neither MCM8 nor MCM10 were associated with the OS of patients with LUAD.

MCMs have frequently been compared with Ki-67, a well-established marker of cell proliferation (62). In adrenocortical cancer, MCM3 and MCM7 share a similar staining pattern with $\mathrm{Ki}-67$ in benign and malignant tissues (63). MCM4 and MCM7 are more sensitive markers than Ki-67 for the detection of esophageal cancer (64). Furthermore, MCM5 and MCM2, but not Ki-67, have been associated with poor prognosis in gastric cancer and NSCLC $(65,66)$. As a marker of G1-phase arrest in mantle cell lymphoma, MCM6 is superior to other clinical parameters, including Ki-67 (48). MCM2 expression is higher than Ki-67 in megakaryocytes, suggesting that MCM2 may be a more sensitive marker for some hematological diseases (67). In tissue sections, MCM proteins are more highly expressed than $\mathrm{Ki}-67$ in quiescent cells $(68,69)$. Taken together, these results suggest that the MCM family may be better proliferation markers than Ki-67 for cancer diagnosis and risk stratification.

In the present study, the expression and prognostic significance of MCMs in LUAD was analyzed. MCM2-6 were found to be upregulated and associated with LUAD prognosis. Notably, high expression of MCM2-5 was associated with reduced OS and PFS. MCM7 expression was also associated with poor OS, and MCM4 predicted worse PPS. As MCM expression was found to be consistent at the mRNA and protein level, analysis of mRNA in patient samples may be preferred as it is easier to analyze. Thus, transcriptional detection of MCM members may provide robust biomarkers to improve patient survival and prognosis prediction in LUAD. 
As all data and results in this study are based on bioinformatic analysis, further studies are required to determine the role of MCMs in vitro and in vivo.

\section{Acknowledgments}

Not applicable.

\section{Funding}

This study was supported by the National Natural Science Foundation of China (grant no. 81572920), the Natural Science Foundation of Zhejiang Province of China (grant no. LY15H160038) and the National Basic Research Program of China (grant no. 2013CB911303).

\section{Availability of data and materials}

The datasets analyzed during the current study are publicly available from the following online databases: Oncomine database (www.oncomine.org); GEPIA database (http:/gepia. cancer-pku.cn/); Kaplan-Meier Plotter (www.kmplot.com); The Human Protein Atlas (https://www.proteinatlas.org/); cBioPortal (http://cbioportal.org); GEO (http://www.ncbi. nlm.nih.gov/geo/); TCGA (https://tcga-data.nci.nih.gov/tcga/); CancerSEA (http://biocc.hrbmu.edu.cn/CancerSEA/).

\section{Authors' contributions}

SL and YX designed the study. SL, ZJ and YL acquired the data, performed data analysis and interpretation. ZJ and YL drafted the manuscript, and YX and SL critically revised it for important intellectual content. All authors gave final approval of the version to be published, and agreed to be accountable for all aspects of the work.

\section{Ethics approval and consent to participate}

This study was performed in accordance with standard guidelines and was approved by the Ethics Committee of the Second Affiliated Hospital, Zhejiang University School of Medicine.

\section{Patient consent for publication}

Not applicable.

\section{Competing interests}

The authors declare that they have no competing interests.

\section{References}

1. Maruthappu M, Watkins J, Noor AM, Williams C, Ali R, Sullivan R, Zeltner T and Atun R: Economic downturns, universal health coverage, and cancer mortality in high-income and middle-income countries, 1990-2010: A longitudinal analysis. Lancet 388: 684-695, 2016.

2. Miller KD, Siegel RL, Lin CC, Mariotto AB, Kramer JL, Rowland JH, Stein KD, Alteri R and Jemal A: Cancer treatment and survivorship statistics, 2016. CA Cancer J Clin 66: 271-289, 2016.
3. Rosell R, Bivona TG and Karachaliou N: Genetics and biomarkers in personalisation of lung cancer treatment. Lancet 382: 720-731, 2013.

4. Tsao MS, Sakurada A, Cutz JC, Zhu CQ, Kamel-Reid S, Squire J, Lorimer I, Zhang T, Liu N, Daneshmand M, et al: Erlotinib in lung cancer-molecular and clinical predictors of outcome. N Engl J Med 353: 133-144, 2005.

5. Paez JG, Jänne PA, Lee JC, Tracy S, Greulich H, Gabriel S, Herman P, Kaye FJ, Lindeman N, Boggon TJ, et al: EGFR mutations in lung cancer: Correlation with clinical response to gefitinib therapy. Science 304: 1497-1500, 2004.

6. Mitsudomi T and Yatabe Y: Mutations of the epidermal growth factor receptor gene and related genes as determinants of epidermal growth factor receptor tyrosine kinase inhibitors sensitivity in lung cancer. Cancer Sci 98: 1817-1824, 2007.

7. SodaM,Choi YL,Enomoto M,Takada S, Yamashita Y,Ishikawa S, Fujiwara S, Watanabe H, Kurashina K, Hatanaka $\mathrm{H}$, et al: Identification of the transforming EML4-ALK fusion gene in non-small-cell lung cancer. Nature 448: 561-566, 2007.

8. Lastwika KJ, Wilson W III, Li QK, Norris J, Xu H, Ghazarian SR, Kitagawa H, Kawabata S, Taube JM, Yao S, et al: Control of PD-L1 expression by oncogenic activation of the AKT-mTOR pathway in non-small cell lung cancer. Cancer Res 76: 227-238, 2016.

9. Facchinetti F, Marabelle A, Rossi G, Soria JC, Besse B and Tiseo M: Moving immune checkpoint blockade in thoracic tumors beyond NSCLC. J Thorac Oncol 11: 1819-1836, 2016.

10. Travis WD, Brambilla E, Burke AP, Marx A and Nicholson AG: Introduction to the 2015 world health organization classification of tumors of the lung, pleura, thymus, and heart. J Thorac Oncol 10: 1240-1242, 2015.

11. Tsao AS, Scagliotti GV, Bunn PA Jr, Carbone DP, Warren GW, Bai C, de Koning HJ, Yousaf-Khan AU, McWilliams A, Tsao MS, et al: Scientific advances in lung cancer 2015. J Thorac Oncol 11: 613-638, 2016.

12. Dirks RA, Stunnenberg HG and Marks H: Genome-wide epigenomic profiling for biomarker discovery. Clin Epigenetics 8: 122, 2016.

13. Johnson EM, Kinoshita Y and Daniel DC: A new member of the MCM protein family encoded by the human MCM8 gene, located contrapodal to GCD10 at chromosome band 20p12.3-13. Nucleic Acids Res 31: 2915-2925, 2003.

14. Bik KT: MCM proteins in DNA replication. Annu Rev Biochem 68: 649-686, 1999.

15. Remus D, Beuron F, Tolun G, Griffith JD, Morris EP and Diffley JF: Concerted loading of $\mathrm{Mcm} 2-7$ double hexamers around DNA during DNA replication origin licensing. Cell 139: 719-730, 2009.

16. Maiorano D, Cuvier O, Danis E and Méchali M: MCM8 is an MCM2-7-related protein that functions as a DNA helicase during replication elongation and not initiation. Cell 120: 315-328, 2005.

17. Lõoke M, Maloney MF and Bell SP: Mcm10 regulates DNA replication elongation by stimulating the CMG replicative helicase. Genes Dev 31: 291-305, 2017.

18. Hua C, Zhao G, Li Y and Bie L: Minichromosome maintenance (MCM) family as potential diagnostic and prognostic tumor markers for human gliomas. BMC Cancer 14: 526, 2014.

19. Peng YP, Zhu Y, Yin LD, Zhang JJ, Guo S, Fu Y, Miao Y and Wei JS: The expressionand prognostic roles of MCMs in pancreatic cancer. PLoS One 11: e0164150, 2016.

20. Kwok HF, Zhang SD, McCrudden CM, Yuen HF, Ting KP, Wen Q, Khoo US and Chan KY: Prognostic signifcance of minichromosome maintenance proteins in breast cancer. Am J Cancer Res 5: 52-71, 2014.

21. Liao X, Liu X, Yang C, Wang X, Yu T, Han C, Huang K, Zhu G, Su H, Qin W, et al: Distinct diagnostic and prognostic values of minichromosome maintenance gene expression in patients with hepatocellular carcinoma. J Cancer 9: 2357-2373, 2018.

22. Werynska B, Pula B, Muszczynska-Bernhard B, Piotrowska A, Jethon A, Podhorska-Okolow M, Dziegiel P and Jankowska R: Correlation between expression of metallothionein and expression of Ki-67 and MCM-2 proliferation markers in non-small cell lung cancer. Anticancer Res 31: 2833-2839, 2011.

23. Wu W, Wang X, Shan C, Li Y and Li F: Minichromosome maintenance protein 2 correlates with the malignant status and regulates proliferation and cell cycle in lung squamous cell carcinoma. Onco Targets Ther 11: 5025-5034, 2018.

24. Fujioka S, Shomori K, Nishihara K, Yamaga K, Nosaka K, Araki K, Haruki T, Taniguchi Y, Nakamura $H$ and Ito $H$ : Expression of minichromosome maintenance 7 (MCM7) in small lung adenocarcinomas (pT1): Prognostic implication. Lung Cancer 65: 223-229, 2009. 
25. Rhodes DR, Kalyana-Sundaram S, Mahavisno V, Varambally R, Yu J, Briggs BB, Barrette TR, Anstet MJ, Kincead-Beal C, Kulkarni P, et al: Oncomine 3.0: Genes, pathways, and networks in a collection of 18,000 cancer gene expression profiles. Neoplasia 9: 166-180, 2007.

26. Tang Z, Li C, Kang B, Gao G, Li C and Zhang Z: GEPIA: A web server for cancer and normal gene expression profiling and interactive analyses. Nucleic Acids Res 45 (W1): W98-W102, 2017.

27. Chansky K, Detterbeck FC, Nicholson AG, Rusch VW, Vallières E, Groome $\mathrm{P}$, Kennedy $\mathrm{C}$, Krasnik M, Peake M, Shemanski L, et al: The IASLC lung cancer staging project: External validation of the revision of the TNM stage groupings in the eighth edition of the TNM classification of lung cancer. J Thorac Oncol 12: 1109-1121, 2017.

28. Pontén F, Jirström K and Uhlen M: The human protein atlas-a tool for pathology. J Pathol 216: 387-393, 2008.

29. Győrffy B, Surowiak P, Budczies J and Lánczky A: Online survival analysis software to assess the prognostic value of biomarkers using transcriptomic data in non-small-cell lung cancer. PLoS One 8: e82241, 2013.

30. Li Q, Birkbak NJ, Gyorffy B, Szallasi Z and Eklund AC: Jetset: Selecting the optimal microarray probe set to represent a gene. BMC Bioinformatics 12: 474, 2011.

31. Gao J, Aksoy BA, Dogrusoz U, Dresdner G, Gross B, Sumer SO Sun Y, Jacobsen A, Sinha R, Larsson E, et al: Integrative analysis of complex cancer genomics and clinical profiles using the cBioPortal. Sci Signal 6: pl1, 2013.

32. Yuan H, Yan M, Zhang G, Liu W, Deng C, Liao G, Xu L, Luo T, Yan H, Long Z, et al: CancerSEA: A cancer single-cell state atlas. Nucleic Acids Res 47 (D1): D900-D908, 2019.

33. Hou J, Aerts J, den Hamer B, van Ijcken W, den Bakker M, Riegman P, van der Leest C, van der Spek P, Foekens J Hoogsteden HC, et al: Gene expression-based classification of non-small cell lung carcinomas and survival prediction. PLoS One 5: e10312, 2010

34. Selamat SA, Chung BS, Girard L, Zhang W, Zhang Y, Campan M, Siegmund KD, Koss MN, Hagen JA, Lam WL, et al: Genome-scale analysis of DNA methylation in lung adenocarcinoma and integration with mRNA expression. Genome Res 22 $1197-1211,2012$

35. Su LJ, Chang CW, Wu YC, Chen KC, Lin CJ, Liang SC, Lin CH, Whang-Peng J, Hsu SL, Chen CH and Huang CY: Selection of DDX5 as a novel internal control for Q-RT-PCR from microarray data using a block bootstrap re-sampling scheme. BMC Genomics 8: 140, 2017.

36. Okayama H, Kohno T, Ishii Y, Shimada Y, Shiraishi K, Iwakawa R, Furuta K, Tsuta K, Shibata T, Yamamoto S, et al: Identification of genes upregulated in ALK-positive and EGFR/KRAS/ALK-negative lung adenocarcinomas. Cancer Res 72: 100-111, 2012.

37. Landi MT, Dracheva T, Rotunno M, Figueroa JD, Liu H, Dasgupta A, Mann FE, Fukuoka J, Hames M, Bergen AW, et al: Gene expression signature of cigarette smoking and its role in lung adenocarcinoma development and survival. PLoS One 3 : e1651, 2008

38. Stearman RS, Dwyer-Nield L, Zerbe L, Blaine SA, Chan Z, Bunn PA Jr, Johnson GL, Hirsch FR, Merrick DT, Franklin WA, et al: Analysis of orthologous gene expression between human pulmonary adenocarcinoma and a carcinogen-induced murine model. Am J Pathol 167: 1763-1775, 2005.

39. Beer DG, Kardia SL, Huang CC, Giordano TJ, Levin AM, Misek DE, Lin L, Chen G, Gharib TG, Thomas DG, et al: Gene-expression profiles predict survival of patients with lung adenocarcinoma. Nat Med 8: 816-824, 2002.

40. Garber ME, Troyanskaya OG, Schluens K, Petersen S, Thaesler Z, Pacyna-Gengelbach M, van de Rijn M, Rosen GD, Perou CM, Whyte RI, et al: Diversity of gene expression in adenocarcinoma of the lung. Proc Natl Acad Sci USA 98: 13784-13789, 2001.

41. Kim KT, Lee HW, Lee HO, Kim SC, Seo YJ, Chung W, Eum HH, Nam DH, Kim J, Joo KM and Park WY: Single-cell mRNA sequencing identifies subclonal heterogeneity in anti-cancer drug responses of lung adenocarcinoma cells. Genome Biol 16: 127, 2015.

42. Simon NE and Schwacha A: The Mcm2-7 replicative helicase: A promising chemotherapeutic target. Biomed Res Int 2014 549719,2014

43. Liu YZ, Wang BS, Jiang YY, Cao J, Hao JJ, Zhang Y, Xu X, Cai $Y$ and Wang MR: MCMs expression in lung cancer: Implication of prognostic significance. J Cancer 8: 3641-3647, 2017.
44. Tachibana KE, Gonzalez MA and Coleman $\mathrm{N}$ : Cell-cycle-dependent regulation of DNA replication and its relevance to cancer pathology. J Pathol 205: 123-129, 2005.

45. Cheung CHY, Hsu CL, Chen KP, Chong ST1, Wu CH, Huang HC and Juan HF: MCM2-regulated functional networks in lung cancer by multi-dimensional proteomic approach. Sci Rep 7: 13302, 2017.

46. Zhang X, Teng Y, Yang F, Wang M, Hong X, Ye LG, Gao YN and Chen GY: MCM2 is a therapeutic target of lovastatin in human non-small cell lung carcinomas. Oncol Rep 33: 2599-2605, 2015.

47. Veena VS, Rajan K, Saritha VN, Preethi Sara G, Chandramohan K, Jayasree K, Thara S and Sujathan K: DNA replication licensing proteins for early detection of lung cancer. Asian Pac J Cancer Prev 18: 3041-3047, 2017

48. Yang J, Ramnath N, Moysich KB, Asch HL, Swede H, Alrawi SJ, Huberman J, Geradts J, Brooks JS and Tan D: Prognostic significance of MCM2, Ki-67 and gelsolin in non-small cell lung cancer. BMC Cancer 6: 203, 2006.

49. Kadara H, Lacroix L, Behrens C, Solis L, Gu X, Lee JJ, Tahara E, Lotan D, Hong WK, Wistuba II and Lotan R: Identification of gene signatures and molecular markers for human lung cancer prognosis using an in vitro lung carcinogenesis system. Cancer Prev Res (Phila) 2: 702-711, 2009.

50. Ramnath N, Hernandez FJ, Tan DF, Huberman JA, Natarajan N, Beck AF, Hyland A, Todorov IT, Brooks JS and Bepler G: MCM2 is an independent predictor of survival in patients with non-small-cell lung cancer. J Clin Oncol 19: 4259-4266, 2001.

51. Ha SA, Shin SM, Namkoong H, Lee H, Cho GW, Hur SY, Kim TE and Kim JW: Cancer-associated expression of minichromosome maintenance 3 gene in several human cancers and its involvement in tumorigenesis. Clin Cancer Res 10: 8386-8395, 2004

52. Xu H, Ma J, Wu J, Chen L, Sun F, Qu C, Zheng D and Xu S: Gene expression profiling analysis of lung adenocarcinoma. Braz J Med Biol Res 49: pii: S0100-879X2016000300601, 2016.

53. Zhang C, Elkahloun AG, Liao H, Delaney S, Saber B, Morrow B, Prendergast GC, Hollander MC, Gills JJ and Dennis PA: Expression signatures of the lipid-based Akt inhibitors phosphatidylinositol ether lipid analogues in NSCLC cells. Mol Cancer Ther 10: 1137-1148, 2011.

54. Yi J, Wei X, Li X, Wan L, Dong J and Wang R: A genome-wide comprehensive analysis of alterations in driver genes in non-small-cell lung cancer. Anticancer Drugs 29: 10-18, 2018.

55. Kikuchi J, Kinoshita I, Shimizu Y, Kikuchi E, Takeda K, Aburatani H, Oizumi S, Konishi J, Kaga K, Matsuno Y, et al: Minichromosome maintenance (MCM) protein 4 as a marker for proliferation and its clinical and clinicopathological significance in non-small cell lung cancer. Lung Cancer 72: 229-237, 2011.

56. Vigouroux C, Casse JM, Battaglia-Hsu SF, Brochin L, Luc A, Paris C, Lacomme S, Gueant JL, Vignaud JM and Gauchotte G: Methyl(R217)HuR and MCM6 are inversely correlated and are prognostic markers in non small cell lung carcinoma. Lung Cancer 89: 189-196, 2015.

57. Fei L, Ma Y, Zhang M, Liu X, Luo Y, Wang C, Zhang H, Zhang $\mathrm{W}$ and Han Y: RACK1 promotes lung cancer cell growth via an MCM7/RACK1/ Akt signaling complex. Oncotarget 8: 40501-40513, 2017.

58. Lo Sardo F, Forcato M, Sacconi A, Capaci V, Zanconato F, Di Agostino S, Del Sal G, Pandolfi PP, Strano S, Bicciato S and Blandino G: MCM7 and its hosted miR-25, 93 and 106b cluster elicit YAP/TAZ oncogenic activity in lung cancer. Carcinogenesis 38: 64-75, 2017.

59. Toyokawa G, Masuda K, Daigo Y, Cho HS, Yoshimatsu M, Takawa M, Hayami S, Maejima K, Chino M, Field HI, et al: Minichromosome Maintenance protein 7 is a potential therapeutic target in human cancer and a novel prognostic marker of non-small cell lung cancer. Mol Cancer 10: 65, 2011.

60. Liu YZ, Jiang YY, Hao JJ, Lu SS, Zhang TT, Shang L, Cao J, Song X, Wang BS, Cai Y, et al: Prognostic significance of MCM7 expression in the bronchial brushings of patients with non-small cell lung cancer (NSCLC). Lung Cancer 77: 176-182, 2012.

61. Cui F, Hu J, Ning S, Tan J and Tang H: Overexpression of MCM10 promotes cell proliferation and predicts poor prognosis in prostate cancer. Prostate 78: 1299-1310, 2018

62. Brown DC and Gatter KC: Ki67 protein: The immaculate deception? Histopathology 40: 2-11, 2002.

63. Aporowicz M, Czopnik P, Kubicka E, Piotrowska A, Dziegiel P, Bolanowski $\mathrm{M}$ and Domoslawski P: Minichromosome maintenance proteins MCM-3, MCM-5, MCM-7, and Ki-67 as proliferative markers in adrenocortical tumors. Anticancer Res 39: 1151-1159, 2019. 
64. Choy B, LaLonde A, Que J, Wu T and Zhou Z: MCM4 and MCM7, potential novel proliferation markers, significantly correlated with $\mathrm{Ki}-67, \mathrm{Bmil}$, and cyclin $\mathrm{E}$ expression in esophageal adenocarcinoma, squamous cell carcinoma, and precancerous lesions. Hum Pathol 57: 126-135, 2016.

65. Giaginis C, Giagini A, Tsourouflis G, Gatzidou E, Agapitos E, Kouraklis G and Theocharis S: MCM-2 and MCM-5 expression in gastric adenocarcinoma: Clinical significance and comparison with Ki-67 proliferative marker. Dig Dis Sci 56: 777-785, 2011.

66. Schrader C, Janssen D, Klapper W, Siebmann JU, Meusers P, Brittinger $G$, Kneba M, Tiemann $M$ and Parwaresch R: Minichromosome maintenance protein 6 , a proliferation marker superior to $\mathrm{Ki}-67$ and independent predictor of survival in patients with mantle cell lymphoma. Br J Cancer 93: 939-945, 2005.
67. Lampert IA, Horncastle D, Dilworth S, Roberts I, Alison MR and Naresh KN: The expression of minichromosome maintenance protein-2 in normal and abnormal megakaryocytes and comparison with the proliferative marker Ki-67. Br J Haematol 131: 490-494, 2005

68. Endl E, Kausch I, Baack M, Knippers R, Gerdes J and Scholzen T: The expression of Ki-67, MCM3, and p27 defines distinct subsets of proliferating, resting, and differentiated cells. J Pathol 195: 457-462, 2001.

69. Chatrath P, Scott IS, Morris LS, Davies RJ, Rushbrook SM, Bird K, Vowler SL, Grant JW, Saeed IT, Howard D, et al: Aberrant expression of minichromosome maintenance protein-2 and Ki67 in laryngeal squamous epithelial lesions. Br J Cancer 89: 1048-1054, 2003.

(c) (i) $(9$ This work is licensed under a Creative Commons Attribution-NonCommercial-NoDerivatives 4.0 International (CC BY-NC-ND 4.0) License. 